\title{
Hubungan Senam Hamil dengan Lama Tidur Ibu Hamil Trimester III di Puskesmas Putri Ayu Kota Jambi
}

\author{
Sri Maharani \\ ProdiDIII Kebidanan, STIKes Baiturrahim Jambi \\ Email: maharanibarus@gmail.com
}

Submitted: $15 / 12 / 2020$

Accepted:12/02/2021

Published: 06/03/2021

\begin{abstract}
Pregnancy is a period that is eagerly awaited by mothers. In conditions of pregnancy there are hormonal and physiological changes. The changes that occur are expected to be carried out by pregnant women in order to have a comfortable pregnancy. Sleep disturbance is one of the complaints that occurs during pregnancy, the complaint is caused by various physiological, hormonal, vascular and metabolic changes. Empirical studies show that up to $25 \%$ of pregnant women report significant sleep disturbances in the first trimester, with rates rising to $75 \%$ in the first trimester. third trimester. Overcoming sleep disorders during pregnancy can be done in various ways in order to stabilize good sleep quality, such as determining a good and comfortable sleeping position while sleeping, basic relaxation exercises, one of which is pregnancy exercise. This study aims to determine the relationship between pregnancy exercise and sleep duration of pregnant women. Quantitative research design. The subjects in this study were pregnant women in their third trimester at Puskesmas Putri Ayu Jambi City. The subjects of the study were seen the length of sleep for pregnant women before doing pregnancy exercise and the length of sleep for pregnant women after participating in pregnancy exercise classes. The research was conducted at the Putri Ayu Health Center, Jambi City. The collected data will be analyzed univariately. It is hoped that the results of this study can be used as a source of information for pregnant women about physiological changes during pregnancy and can overcome complaints of difficulty sleeping by doing pregnancy exercise.
\end{abstract}

Keywords: exercise for pregnancy, pregnant women, sleep duration

Abstrak
Kehamilan merupakan suatu masa yang sangat dinantikan oleh ibu. Dalam kondisi kehamilan terjadi perubahan hormonal dan fisiologis. Perubahan yang terjadi diharapkan dapat dijalani oleh ibu hamil agar menjalani kehamilan dengan nyaman. Gangguan tidur merupakan salah satu keluhan yang terjadi selama kehamilan, keluhan tersebut disebabkan oleh berbagai perubahan fisiologis, hormonal, vaskular dan metabolism.studi empiris menunjukkan bahwa hingga $25 \%$ wanita hamil melaporkan gangguan tidur yang signifikan pada trimester pertama, dengan angka naik menjadi 75\% pada trimester ke III. Mengatasi gangguan tidur pada masa kehamilan dapat dilakukan dengan berbagai macam cara agar menstabilkan kualitas tidur yang baik seperti menentukan posisi tidur yang baik dan nyaman saat tidur, latihan relaksasi dasar, salah satunya dengan senam hamil. Penelitian ini bertujuan untuk melihat hubungan senam hamil terhadap lama tidur ibu hamil. Desain penelitian kuantitatif. Subjek dalam penelitian ini adalah ibu hamil trimester III di Puskesmas Putri Ayu Kota Jambi. Subjek penelitian dilihat lama tidur ibu hamil sebelum dilakukan senam hamil dan dilihat lama tidur ibu hamil setelah mengikuti kelas senam hamil.Penelitian dilakukan di Puskesmas Putri Ayu Kota Jambi. Data yang terkumpul akan 
dianalsisi secara univariat. Diharapkan hasil penelitian ini dapat dijadikan sumber informasi bagi ibu hamil mengenai perubahan fisiologis selama hamil dan dapat mengatasi keluhan sulit tidur dengan melakukan senam hamil.

Kata Kunci: ibu hamil , lama tidur, senam hamil

\section{PENDAHULUAN}

Seorang ibu tentunya sangat mendambakan kehamilan, dimana setiap ibu sangat menanti adanya kehamilan pada dirinya. Selama kehamilan kehamilan terjadi perubahan hormonal dan fisiologis. Perubahan yang terjadi diharapkan dapat dijalani oleh ibu hamil agar menjalani kehamilan dengan nyaman. Perubahan yang biasa dialami oleh ibu merupakan perubahan fisiologis dimana dimulai setelah pembuahan dan mempengaruhi sistem organ dalam tubuh. Perubahan yang terjadi mempengaruhi farmakokinetik (penyerapan, distribusi, metabolism dan eliminasi dan sifat farmakodinamik setiap orang yang berbeda).(Shagana, Dhanraj, Jain, \& Nirosa, 2018).

Ada kalanya seseorang mengalami gangguan tidur yang merupakan salah satu keluhan yang sering terjadi selama kehamilan, keluhan tersebut disebabkan oleh berbagai perubahan fisiologis, hormonal, vaskular dan metabolism.studi empiris menunjukkan bahwa hingga $25 \%$ wanita hamil melaporkan gangguan tidur yang signifikan pada trimester pertama, dengan angka naik menjadi $75 \%$ pada trimester ke III. (Okun, Schetter, \& Glynn, 2011).

Gangguan tidur yang sering dialami secara klinis terjadi selama kehamilan dapat dikaitkan dengan kejadian preeklampsia, persalinan memanjang, peningkatan pertolongan persalinan dengan section caesaria, depresi pasca partum dan kelahiran prematur. Selain itu dapat disimpulkan pula bahwa kemungkinan gangguan tidur dapat berhubungan dengan stres psikososial dan kelahiran prematur.(Okun et al., 2011)

Salah satu cara mengatasi gangguan tidur pada masa kehamilan yaitu dengan

melakukan berbagai macam cara agar menstabilkan kualitas tidur yang baik seperti menentukan posisi tidur yang baik dan nyaman saat tidur, latihan relaksasi dasar, salah satunya dengan senam hamil. senam hamil dapat berdampak positif untuk mengatasi gangguan tidur. (N, Marwiyah, 2018).

Olahraga merupakan salah satu upaya yang dapat merileksasikan tubuh, melancarkan peredaran darah ibu dan mengaktifkan otot-otot ibu. Olah raga yang dapat dilakukan oleh ibu hamil salah satunya dengan senam hamil, senam hamil merupakan latihan gerak yang diberikan pada ibu untuk menjadikan tubuh yang sehat dan bugar. Oleh karena itu, selain makan secara teratur, ibu hamil harus cukup istirahat dan berolahraga sesuai dengan kebutuhannya, salah satu olahraga yang baik untuk ibu hamil adalah senam hamil. Senam hamil merupakan terapi latihan gerak yang diberikan pada ibu hamil untuk mempersiapkan dirinya baik fisik maupun mental dalam menghadapi persalinan.

Hasil penelitian yang dilakukan oleh nila marwiyah dengan judul pengaruh senam hamil terhadap kualitas tidur ibu hamil trimester II dan III dikelurahan Margaluyu Wilayah kerja Puskesmas Kasemen dengan hasil terdapat pengaruh kualitas tidur setelah dilakukan perlakuan senam hamil pada ibu.(N, Marwiyah, 2018)

Tujuan penelitian ini adalah untuk mengetahui hubungan senam hamil dengan lama tidur ibu hamil trimester III di Puskesmas Putri Ayu Kota Jambi.

\section{METODE PELAKSANAAN}

Penelitian ini menggunakan rancangan kuantitatif untuk mencari hubungan senam hamil terhadap lama tidur 
ibu hamil. Rancangan penelitian ini menggunakan satu kelompok subjek. Sampel pada penelitian ini adalah adalah ibu hamil trimester III yang memenuhi kriteria inklusi. Besar sampel dihitung menggunakan rumus Arikunto (2007) total sampling dari total populasi sebanyak 30 orang. Alat pengumpulan data diambil dari lembar observasi ibu hamil yang ada di Puskesmas Putri Ayu.
Pelaksanaan penelitian keseluruhan selama 5 bulan mulai dari bulan Maret-Juli Tahun 2020 di Wilayah Kerja Puskesmas Putri Ayu Kota Jambi. Penentuan lokasi dilakukan dengan pertimbangan jumlah kunjungan ibu hamil terbanyak diKota Jambi adalah di Puskesmas Putri Ayu Kota Jambi.

\section{HASIL DAN PEMBAHASAN}

Tabel 1. Gambaran Pelaksanaan senam hamil di Puskesmas Putri Ayu Kota Jambi

\begin{tabular}{clcc}
\hline No & \multicolumn{1}{c}{ Umur } & Frekuensi & Persentase \\
\hline 1 & Mengikuti & 18 & 60 \\
2 & Tidak mengikuti & 12 & 40 \\
\hline \multicolumn{1}{c}{} & 30 & 100.0 \\
\hline Berdasarkan hasil penelitian pada tabel & $\begin{array}{l}\text { mengikuti } \\
\text { diatas diperoleh data bahwa ibu yang }\end{array}$ & sebanyak 18 ibu (60\%).
\end{tabular}

Tabel 2. Gambaran Lama Tidur Ibu Hamil yang Mengikuti Senam Hamil di Puskesmas Putri Ayu Kota Jambi

\begin{tabular}{|c|c|c|c|}
\hline No & Umur & Frekuensi & Persentase \\
\hline 1 & Baik & 16 & 88,9 \\
\hline 2 & Kurang baik & 2 & 11,1 \\
\hline
\end{tabular}

Berdasarkan hasil penelitian pada tabel memiliki lama tidur yang baik yaitu 28 ibu diatas diperoleh data bahwa ibu hamil yang $\quad(93,3 \%)$. mengikuti senam hamil paling banyak

Tabel 3. Gambaran Lama Tidur Ibu Hamil yang tidak Mengikuti Senam Hamildi Puskesmas Putri Ayu Kota Jambi

\begin{tabular}{|c|c|c|c|}
\hline No & Umur & Frekuensi & Persentase \\
\hline 1 & Baik & 5 & 41,7 \\
\hline 2 & Kurang baik & 7 & 58,3 \\
\hline
\end{tabular}

Berdasarkan hasil penelitian pada tabel memiliki lama tidur yang kurang baik yaitu diatas diperoleh data bahwa ibu hamil yang $7 \mathrm{ibu}(58,3 \%)$. 
pada usia reproduktif $20-35$ tahun yaitu 23 ibu $(76,7 \%)$, berdasarkan karakterisktik pekerjaan ibu hamil paling banyak bekerja sebagai IRT yaitu 25 ibu $(83,3 \%)$ dan berdasarkan pendidikan ibu paling banyak pendidikan ibu sampai SMA yaitu $21 \mathrm{ibu}$ $(70 \%)$.

Senam hamil adalah salah satu olahraga yang dapat dilakukan oleh ibu hamil pada trimester III merupakan aktivitas fisik yang, meningkatkan elastisitas otot panggul dan ligamentum serta menurunkan kejadian perdarahan selama dan sesudah bersalin serta dapat menurunkan kejadian fetal distress. Senam hamil merupakan suatu alternatif dalam mengurangan terjadinya stress fisik akibat kehamilan, seperti mengurangi kram kaki, dan punggung, meningkatkan kemampuan ibu untuk adaptasi dengan adanya perubahan pada tubuhnya.(Syahrul, 2013)

Menjadikan suatu kehamilan yang nyaman dan menyenangkan American College of Obstetricans and Gynecologist (ACOG) merekomendasikan senam sebagai upaya preventif pada ibu agar proses kahamilan dan persalinan berjalan secara alamiah, dan mengurangi krisis akibat persalinan.(Syahrul, 2013)

Dapat dilihat dari penelitian yang dilakukan yang memiliki hasil penelitian didapatkan hasil dari 30 orang ibu hamil trimester III 18 diantaranya sudah melakukan senam hamil $(60 \%)$. Dari 18 orang ibu hamil yang mengikuti senam hamil 16 orang ibu dinyatakan memiliki waktu tidur yang baik yaitu $>7$ jam $(88,9 \%)$.

Ibu hamil yang memiliki aktifitas yang baik ditandai dengan tidur yang cukup sehingga akan membuat ibu hamil lebih bugar dan sehat sehingga dapat beraktifitas dengan baik, janin yang dikandungnya pun akan tumbuh dengan sehat. Oleh karena itu, ibu hamil harus mengupayakan agar kecukupan tidurnya terpenuhi, yakni sekitar 7-8 jam perhari.Kebutuhan ini bisa terpenuhi dari tidur malam atau di kombinasikan dengan tidur siang.Jika tidur malam hanya bisa dilakukan 5-6 jam maka tidur siang perlu dilakukan 1-2 jam sehingga kebutuhan tidur tercukupi. Lebih baik lagi bila ibu hamil tidur hingga 9 jam perhari.(N, Marwiyah, 2018)

National Sleep Foundation (2007) menyatakan bahwa 97,3 \% wanita hamil trimester ketiga selalu terbangun dimalam hari dan rata - rata sekitar $78 \%$ wanita hamil di Amerika mengalami gangguan tidur. Menurut Reichner (2015) mengatakan bahwa gangguan pola tidur pada trimester pertama sebanyak $13 \%$, trimester kedua $19 \%$ dan meningkat di trimester akhir yaitu sebesar $66 \%$. Fernandez-Alfonson, TrabalonPastor (2012) mengatakan bahwa dari $73,5 \%$ ibu hamil yang mengalami insomnia terjadi pada kehamilan 39 minggu, dimana insomnia ringan sebanyak $50,5 \%$, insomnia sedang $15,7 \%$ dan insomnia berat sebanyak $3,8 \%$. (N, Marwiyah, 2018)

Dalam mengatasi kesulitan tidur yang sering terjadi pada ibu hamil, dapat dilakukan beberapa upaya lain antara lain dengan melakukan olahraga ringan yang aman untuk ibu hamil, hipnoterapi, memberikan pendidikan kesehatan bagaimana menjaga kualitas tidur dan latihan relaksasi (Hegard, dalam Marwiyah 2018). Salah satu upaya yang dapat dilakukan yaitu dengan menlakukan olah raga di pagi hari seperti jalan-jalan pagi hari atau olahraga yang bersifat kelompok seperti senam hamil bisa dilakukanuntuk memperlancar sirkulasi darah ibu dan meningkatkan relaksasi pada ibu hamil bisa dilakukan secera rutin (Roosytasari, dalam Marwiyah 2018).

Gangguan tidur dapat terjadi pada ibu hamil seiring bertambah usia kehamilan, untuk menangani masalah ganggun tidur pada ibu hamil, kita dapat memberikan beberapa metode untuk menstabilkan kualitas tidur yang baik, seperti menentukan posisi yang baik dan nyaman saat tidur, latihan relaksasi dasar, salah 
satunya dengan senam hamil. melakukan senam hamil dapat berdampak positif untuk mengatasi gangguan tidur.(Brayshaw dalam Marwiyah 2018)

Penelitian Wahyuni dan Ni'mah (2012) menunjukkan bahwa senam hamil berpengaruh dalam peningkatan durasi tidur ibu hamil pada trimester III.Terdapat 9 ibu hamil trimester III yang melakukan senam hamil selama 4 minggu, dengan pertemuan $2 x$ dalam satu minggu. Waktu senam hamil adalah $\leq 30$ menit.Penelitian ini juga menyatakan bahwa senam hamil akan memberikan efek relaksasi pada ibu hamil yang bisa berpengaruh terhadap peningkatan durasi tidur bagi ibu hamil.

$$
\text { Penelitian Aliyah }
$$

menunjukkan bahwa senam hamil berpengaruh dalam meningkatkan durasi tidur ibu hamil trimester III. Penelitian dilakukan pada 22 da ibu hamil trimester II dan III dengan jumlah pertemuan adalah 6 kali pertemuan, 2 kali dalam seminggu. Penelitian ini juga menyatakan bahwa senam hamil memberikan efek relaksasi pada ibu hamil yang bisa berpengaruh terhadap durasi tidur bagi ibu hamil.

\section{SIMPULAN}

Dari hasil yang didapatkan pada penelitian yang dilakukan di Puskesmas Putri Ayu tahun 2020, dapat disimpulkan bahwa ibu yang mengikuti senam hamil yaitu sebanyak $18 \mathrm{ibu}(60 \%)$. Ibu hamil yang mengikuti senam hamil memiliki lama tidur yang baik adalah $16 \mathrm{ibu}$ dari $18 \mathrm{ibu}$ $(88,9 \%)$. Ibu hamil yang tidak mengikuti senam hamil dan memiliki lama tidur yang kurang baik adalah 7 ibu dari 12 ibu $(58,3 \%)$.

\section{SARAN}

Perlu meningkatkan pengetahuan masyarakat tentang perkembangan inovasi dalam menjalani kehamilan dengan nyaman, agar ibu hamil merasa nyaman selama menjalani kehamilan sehingga memiliki dampak pemilihan persalinan secara normal tanpa rasa takut.

\section{UCAPAN TERIMAKASIH}

Terima kasih saya ucapkan kepada STIKes Baiturrahim Jambi yang memberikan support dan memberikan pendanaan dalam pelaksanaan penelitian. Selain itu terima kasih pula kepada instansi tempat pelaksanan atas kerjasamanya.

\section{DAFTAR PUSTAKA}

Aliyah, J. (2016). Pengaruh Pemberian Senam Hamil Terhadap Tingkat Kecemasan Dan Kualitas Tidur Ibu Hamil Di Puskesmas Samata Kabupaten Gowa Makassar :Skripsi.Program Studi Fisioterapi Fakultas Kedokteran Universitas Hasanuddin.

repository.unhas.ac.id/handle/1234567 89/19340

N, Marwiyah, S. F. (2018). Pengaruh Senam Hamil Terhadap Kualitas Tidur Ibu Hamil Trimester II dan III di Kelurahan Margaluyu Wilayah Kerja Puskesmas Kasemen. Faletehan Helath Journal, 5(3), 123-128.

Okun, M. L., Schetter, C. D., \& Glynn, L. M. (2011). Aasm.34.11.1493. 24-26. https://doi.org/10.5665/sleep.1384

Shagana, J. A., Dhanraj, M., Jain, A. R., \& Nirosa, T. (2018). Physiological changes in pregnancy. Drug Invention Today, 10(8), 1594-1597.

Syahrul, F. (2013). Pengaruh Senam Hamil Terhadap Proses Persalinan Dan Status Kesehatan Neonatus Pregnancy Exercise Infl uence In Labor And Neonatal Health Status. 316-324.

Wahyuni, dan Layinatun, N. (2012).Manfaat Senam Hamil Untuk Meningkatkan Durasi Tidur Ibu Hamil. http://journal.unnes.ac.id.

Whalley J, Simkin P, K. A. (2008). kehamilan dan persalinan (2 ed.; S. K, ed.). Jakarta: Bhuana Ilmu Populer. 